\title{
CLASSE TRABALHADORA E RACISMO DURANTE A PANDEMIA: Eugenia e Fascismo no governo Bolsonaro.
}

\author{
Robson de Oliveira ${ }^{1}$ - Universidade Federal do Paraná. \\ Ana Luíza Tavares Bruinjé ${ }^{2}$ - Universidade Federal do Paraná.
}

\begin{abstract}
Resumo
O presente artigo apresenta a formação da classe trabalhadora no Brasil por meio de seus traços racistas para refletir sobre os efeitos da pandemia da COVID-19 nos trabalhadores pretos, pobres e periféricos. Na apreensão do referencial teórico e substrato empírico, apoia-se sobre o método crítico dialético e, como técnica principal, a pesquisa bibliográfica sobre os temas: classe trabalhadora, racismo, eugenia e fascismo. A questão norteadora do artigo é: sendo o racismo traço estrutural na formação da classe trabalhadora no Brasil, quais os efeitos da racionalidade eugênica e fascista emanada do governo na pandemia da COVID-19? Para isso, o texto parte de análises realizadas por intelectuais sobre a formação sócio-histórica com enfoque nos elementos raciais da classe trabalhadora e os efeitos deletérios da racionalidade eugênica e fascista emanada do governo que trata como descartáveis milhares de trabalhadores. Palavras-chave: Classe Trabalhadora; Racismo; COVID-19; Eugenia; Fascismo.
\end{abstract}

\section{WORKING CLASS AND RACISM: Eugenics and Fascism in the Bolsonaro's government during the pandemic.}

\begin{abstract}
This article presents the formation of the working class in Brazil through its racist traits to reflect on the effects of the COVID-19 pandemic among black, poor, and peripheral workers. The apprehension of the theoretical reference and empirical substratum relies on the dialectical critical method and the primary technique is the bibliographic research on the themes: workingclass, racism, eugenics, and fascism. The guiding question of the article is: since racism is a structural feature in the shaping of the working class in Brazil, what are the effects of the eugenic and fascist rationality emanated from the government in the COVID-19 pandemic? To this end, the text is based on analyses carried out by scholars on socio-historical formation with a focus on racial elements of the working class, and the deleterious effects of eugenic and fascist rationality emanated from the government that regards thousands of workers as disposable.
\end{abstract}

Keywords: Working-class; Racism; COVID-19; Eugenics; Fascism.

\footnotetext{
1 - Doutor em Serviço Social pela Universidade Federal de Santa Catarina. Professor do curso de Serviço Social da Universidade Federal do Paraná. - e-mail: robson.de.oliveira@ufpr.br

2 - Graduada em Serviço Social pela Universidade Federal do Paraná. - e-mail: analuizabruinje@gmail.com
} 


\section{INTRODUÇÃO}

Em tempos de pandemia mundial e crise do capital, o acirramento da luta de classes nos impõe a necessidade de revisão histórica das relações sociais, levando em conta o desenvolvimento das forças produtivas internacionais, com foco na particularidade brasileira. A produção teórica aqui apresentada é voltada para elementos necessários à compreensão do atual quadro da luta de classes no Brasil, levando em conta as categorias fundamentais: raça e classe.

Abordamos no texto, de maneira inicial, os elementos que dão base à constituição da classe trabalhadora no Brasil (IANNI, 1972) e as formas de reprodução e consolidação do racismo estrutural (ALMEIDA, 2019). Partimos do ponto que a análise da realidade descolada desses elementos e do processo de institucionalização e estruturação dos mesmos na ossatura do Estado, reproduzem e naturalizam o racismo como tecnologias modernas de incremento da taxa de lucro ignorando assim a complexidade do processo de exploração da força de trabalho mediante a formação socio-histórica da classe trabalhadora no Brasil.

Na sequência, apresentamos uma discussão teórica geral da implementação de teorias racistas e eugênicas no desenvolvimento industrial do então emergente Estado Nacional brasileiro. Os elementos históricos e ideológicos, que esse debate traz, nos permite a fundamentação da premissa apresentada acima, além de ampliar a noção de reprodução sistemática e estrutural da desigualdade de classe no Brasil, no que se refere à classe trabalhadora e sua exploração.

Por fim, identificamos e analisamos acontecimentos sociais contemporâneos em tempos de pandemia do novo coronavírus, a COVID-19. Ressaltamos, também, a atuação do Governo Federal e o (des)trabalho realizado no tocante à manutenção da vida, principalmente de vidas pretas, pobres e periféricas, ou seja, da classe trabalhadora. A hipótese é que, se não fizermos a leitura de realidade indicada acima de maneira crítica, as mortes provocadas pelo vírus durante a pandemia podem soar como "mortes inevitáveis" resultantes de "um vírus democrático" por uma suposta "equalização" no que se refere o risco de contágio. Destacamos as condições objetivas e subjetivas de distanciamento social entre as classes fundamentais e, principalmente, no segmento majoritário da classe trabalhadora, de homens e mulheres negras. 
O presente artigo, na apreensão do referencial teórico e análise do substrato empírico, apoia-se sobre o método crítico dialético e, como técnica principal, utiliza-se da pesquisa bibliográfica para abordar o tema. A questão que norteia esse artigo é: sendo o racismo traço estrutural na formação da classe trabalhadora no Brasil, quais os efeitos disso na racionalidade eugênica e fascista emanadas do governo federal durante a pandemia da COVID-19? Para sua resposta, a pesquisa foi realizada através de leitura e análise dos referenciais bibliográficos e notícias jornalísticas publicadas em meios físicos e virtuais.

\section{A PARTICULARIDADE DA CLASSE TRABALHADORA NO BRASIL: raça e racismo como elementos histórico-estruturais}

A construção do Estado moderno brasileiro, enquanto partícipe do ciclo internacional do capital em seu papel periférico e colonizado, é constituída internamente pelas relações de força entre classes no modo de produção capitalista entre exploradores e explorados/as. No processo dialético de constituição do capitalismo, a exploração das colônias americanas foi um elemento nodal para a consolidação da dominação inglesa sobre o continente americano por meio da influência que exercia sobre Espanha e Portugal (cf. BAMBIRRA, 2013) e o posterior imperialismo e capitalismo monopolista (cf. NETTO, 2011).

Todavia, nosso processo de formação da classe trabalhadora requisita atenção, à medida que a constituição histórica de nossa população é distinta da observada nos feudos europeus, gérmen da constituição da classe burguesa e trabalhadora predominante no desenvolvimento do modo de produção. O Brasil é um país colonizado cuja exploração da força de trabalho, em seus primeiros séculos, apoiava-se na escravidão de povos originários e africanos sequestrados, o que impõe distinções na análise.

Ao responder Proudhon em sua afirmação de que qualquer categoria econômica possuiria um lado bom e outro mau, Marx desconstruiu tal assertiva partindo da escravidão, enquanto categoria econômica, como "qualquer outra": 


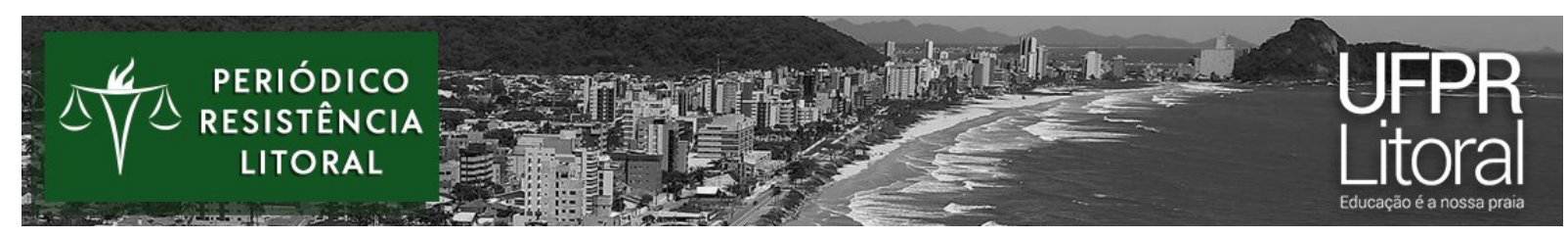

A escravidão direta é o eixo da indústria burguesa, tal como as máquinas, o crédito etc. Sem a escravidão não há algodão; sem algodão não há indústria moderna. Foi a escravidão que deu às colônias o seu valor, foram as colônias que criaram o comércio mundial, que é a condição da grande indústria. [...]. Por isso a escravidão, por ser uma categoria econômica, sempre existiu nas instituições dos povos. Os povos modernos só souberam disfarçar a escravidão em seu próprio país e impondo-a sem disfarce ao novo mundo. (MARX, 2007, p. 102).

Essa requisição analisada por Marx para compreender a escravidão moderna precisa ser deslindada para compreendermos a constituição da classe trabalhadora. No caso do Brasil Colônia, partimos do sequestro e tráfico da população do continente africano, destinado ao abastecimento de mão de obra nas colônias Americanas ${ }^{3}$. Até o princípio do século XIX, já haviam sido trazidos ao Brasil, aproximadamente, cinco a seis milhões de homens e mulheres africanas sequestradas, cabendo ressaltar que do total que desembarcavam nas colônias americanas, 40\% tiveram como destino final o Brasil (SCHWARCZ; STARLING, 2015).

Há dois traços oriundos da escravidão que tangenciam a forma como essa exploração aviltante era apreendida no Brasil Colônia: o trabalho como indigno quando realizado por um europeu e a disciplinarização do/a africano/a escravizado/a por via do trabalho (SCHWARCZ; STARLING, 2015). A disciplinarização do corpo do escravo era tão importante que se elaboravam manuais, orientando os senhores de escravos na aplicação de castigos sem que isso "danificasse" excessivamente o semovente ${ }^{4}$.

A transição do sujeito escravizado em trabalhador livre é formal e parcialmente explicada pela abolição. Requisita, ainda assim, ser analisada junto a processos econômicos e sociais diversos que, entre outros, incentivaram o afluxo de imigrantes europeus, o deslocamento de roceiros entre as fazendas de café e o fomento dos núcleos urbanos no ascendente processo de industrialização. A forma como a força de trabalho se inseriu no

\footnotetext{
${ }^{3}$ A escravidão na organização lusitana foi anterior em quase um século à "descoberta do Brasil", havendo atividades portuguesas registradas em 1453 nas margens do rio Senegal. O interesse dos portugueses nesse local se voltava às jazidas de ouro; já o tráfico de africanos se destinava nesse período, massivamente, à utilização da mão de obra para o cumprimento de tarefas domésticas em Portugal. Em meados do século XVI, Lisboa era a cidade europeia com maior número de escravos (SCHWARCZ; STARLING, 2015).

${ }^{4}$ Um exemplo documentado sobre essas práticas, o castigo a ser infligido aos escravos para sua disciplinarização no trabalho, pode ser verificado no livro Manual do Agricultor Brasileiro, escrito por Carlos Augusto Taunay em 1839. O capítulo 2 Da Escravidão - Dos escravos pretos e o capítulo 3 Da Disciplina da escravatura versavam sobre a alimentação, vestimenta, rotina e, principalmente, sobre as formas de castigo mais viáveis que não danificassem o "semovente", assegurando sua eficácia e obediência. "Vimos como a perpétua vigilância dos feitores e administradores ou senhores era precisa para conduzir os pretos ao trabalho, mas esta vigilância seria ilusória sem os castigos, os quais devem ser determinados com moderação, aplicados com razão, proporcionados à qualidade da culpa e conduta do delinquente, e executado à vista de toda a escravatura, com a maior solenidade, servindo assim o castigo de um para ensinar e intimidar os mais (TAUNAY, 2001, p. 67)
} 


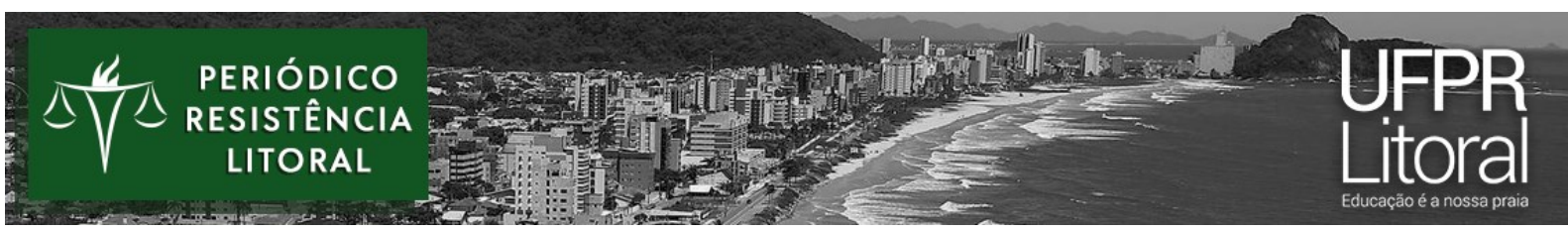

processo produtivo e nas condições reais da economia nacional a partir do século XIX, elucidam as mudanças tangenciadas desde a composição e estruturação da camada de trabalhadores e produtores de valor. Em síntese, a imigração de europeus e a abolição da escravidão são componentes contributivos e definidores da formação da classe trabalhadora no Brasil (IANNI, 1972), contudo o autor explica que:

O regime (escravocrata) representa um obstáculo à expansão da racionalidade indispensável à aceleração da produção de lucro. Como a economia nacional estava organizada para produzir mercadorias, isto é, lucro, a empresa exigia a renovação contínua, tanto em sua organização geral como planejamento da utilização dos fatores. Por isso impõe-se a transformação do escravo em trabalhador livre, daquele que é o meio de produção assalariado. Em outras palavras, a mão-de-obra, simplesmente transforma-se em força de trabalho no sentido de fator adequado à produção de lucro. Ao transformar o escravo em trabalhador livre, o que ocorre é a libertação da empresa do ônus da propriedade de um "fator" que agora só interessa pela sua capacidade de produzir valor. A libertação do escravo é o processo pelo qual se dá um avanço na constituição das condições racionais indispensáveis à produção crescente de lucro. (IANNI, 1972, p. 382).

Para ser mercadoria, a força de trabalho demanda um/a trabalhador/a livre, sendo assim comprada mediante as necessidades oriundas da produção de lucro. O ciclo de industrialização no Brasil iniciado na segunda metade do século XIX, ao ser investido pela economia nacional, só é viável com a separação plena entre o trabalhador/a e os meios de produção. Já no plano moral, a princípio, a escravidão estava fadada a ser superada pelas "contradições insuportáveis para os agentes da situação e para os grupos sociais identificados com a civilização urbana florescente". (IANNI, 1972, p. 383).

Em um plano mais geral, o escravo é um trabalhador cuja atividade se organiza segundo um padrão de racionalidade própria do regime de produção mercantil. No regime escravocrata, nos termos em que ele se organizou no Brasil, o escravo aparece na condição de meio de produção. A maneira pela qual ele é incorporado na estrutura do empreendimento, ao lado da terra, da tecnologia, da matéria prima, dão-lhe o caráter de um entre outros meios de produção. O escravo é comprado, alugado, emprestado, dado de presente ou vendido, como coisa ou como semovente. [...]. Entretanto, enquanto capital aplicado, a sua vida produtiva está sujeita a fuga, a doença, à incapacidade temporária ou permanente, à morte. Isso significa que, enquanto meio de produção, o valor do escravo é suscetível de flutuações bruscas, inclusive reduzindo-se a zero. Em outros termos, num momento o escravo representa a aplicação de uma soma relativamente elevada de capital, tendo-se em vista que corresponde a investimento para vários anos. Ao passo que no instante seguinte corresponder a uma perda total. (IANNI, 1972 p. 395).

Revista Resistência Litoral (Matinhos PR), Vol. 1 N. 1 p. 29 - 44, jan/jun de 2022. ISSN: 2764-3174

DOI: http://dx.doi.org/10.5380/rrl.v1i1.79294

Direitos Autorais: https://creativecommons.org/licenses/by/4.0/deed.pt_BR 


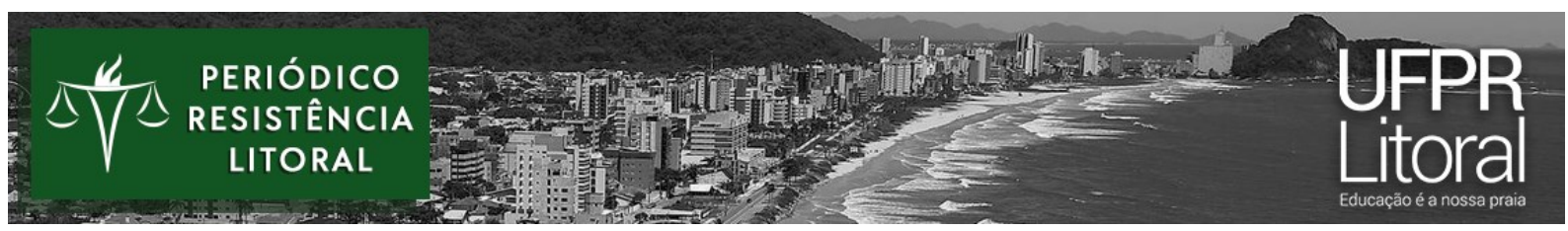

Em virtude do gradativo processo de modernização da sociedade brasileira, a escravidão em certo momento representou um entrave ao desenvolvimento salutar do mercado interno, principalmente, pela particularidade de não separação da força de trabalho e trabalhador/a na necessidade de tutela inteira da vida de quem compra essa força de trabalho.

Antes da alforria em 1888, os processos migratórios de europeus visando a constituição de outro tipo de mão de obra e o embranquecimento do país já tinham começado. É importante acenar que a forma como os imigrantes europeus foram incluídos nas tarefas produtivas desencadeou conflitos com os/as escravizados/as, ex-escravizados/as e seus/suas descendentes. Isso se deu pela tendência das fazendas, fábricas e empresas a contratarem, preferencialmente, imigrantes para o exercício dessas atividades que fossem "conacionais" dos proprietários (cf. IANNI, 1972).

As dificuldades que os afrodescendentes tinham para se inserir nessas atividades resultaram na presença desse grupo no interior das nascentes cidades sem conseguirem inserção plena nos processos produtivos, o que acabou por agravar o que se pode chamar de anomia social, que foi transplantada do cativeiro para a reprodução da vida social, agora como "trabalhador livre".

O que Ianni (1972) reitera a partir disso é que a própria estrutura da classe trabalhadora se constituiu no Brasil por via do preconceito racial. Ou seja, pela sua formação sócio-histórica, o Brasil é atravessado pelo racismo enquanto processo estrutural econômico e político, pelo autoritarismo na fundação do Estado, por disputas intraclasses da burguesia entre a "modernização" industrial e pela manutenção dos privilégios dos grupos dominantes (CASIMIRO, 2018). E, somado a isso, o inegável corte racial no interior da constituição da classe trabalhadora e a empresa do embranquecimento da nação. Almeida (2019) concorda com as análises acima e afirma que:

Em resumo: o racismo é uma decorrência da própria estrutura social, ou seja, do modo "normal" como que se constituem as relações políticas, econômicas, jurídicas e até familiares, não sendo uma patologia social e nem um desarranjo institucional. O racismo é estrutural. [...] O que o racismo, como processo histórico e político cria são as condições sociais para que, direta ou indiretamente, grupos racialmente identificados sejam discriminados de forma sistemática (ALMEIDA, 2019, 50-51).

Uma característica inerente à formação da questão social e, portanto, da luta de classes no Brasil, alojada diretamente na formação da classe trabalhadora em sua relação direta entre o 


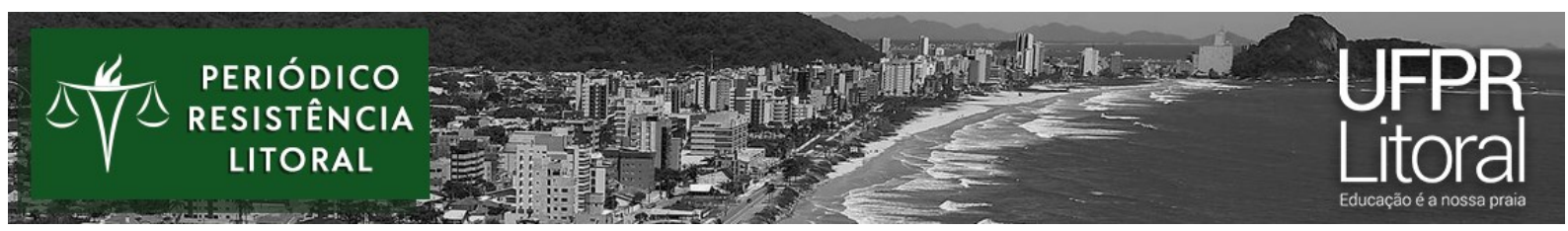

pleno funcionamento do capitalismo e a existência de trabalhadores/as "livres", em igualdade de condições para ofertar sua força de trabalho no mercado interno. A formação social brasileira aponta muito claramente para a segregação social da população negra, conforme Almeida (2019), sendo realizada de maneira individual, institucional e principalmente, estrutural. O racismo como processo sistemático de discriminação favorece as bases sociais burguesas e contribui para processo histórico de construção do imaginário social acerca da população negra, da perspectiva racista de hegemonia branca e do aumento da taxa de exploração da mais-valia pela desvalorização da força de trabalho da população negra.

O resultado disso é crível na história e na contemporaneidade, com a reserva dos piores trabalhos, menores salários, violência, genocídio e negligência na implementação de políticas públicas e sociais que considere o corte racial em sua consecução (GONZALEZ, 2020). Essa miscelânia, que abarca nosso passado como colônia, as práticas herdadas do escravismo e a abolição da escravatura enquanto processo que assegurou os privilégios das classes detentoras do capital no lugar da conformação de cidadão livre e de direitos sociais aos alforriados, compõe o que Almeida (2019) denomina de racismo estrutural.

Para assegurar alguma forma de consenso, para além da violência da coerção expressas no genocídio da população negra, criou-se o recurso ao mito da democracia racial - que possui em Oliveira Vianna e Gilberto Freyre seus principais precursores -, o "multiculturalismo", atravessado pela ideologia da meritocracia e do individualismo que, concatenados ao projeto de branqueamento da nação, resultam no discurso de que somos uma nação sem racismo e segregação. Essas ideologias adscritas acima atuam como ferramentas ao funcionamento da democracia burguesa e capitalismo monopolista desenvolvido no país. Conforme Almeida (2019), para além de uma suposta revolução interior ou evolução espiritual, o que se coloca como imprescindível para a superação desse cenário são mudanças no quadro econômico e político que determinam mudanças estruturais herdadas de um país ex-colônia construído sobre o alicerce da escravidão.

Dentro desse amplo conjunto de indicações acerca da constituição da classe trabalhadora no Brasil e as características oriundas do racismo estrutural, é necessário interrogar sobre a forma como a classe trabalhadora se encontra submetida à excepcionalidade do quadro de pandemia. No interior desta classe, reconhecendo a condição de indivíduo precarizado em virtude de sua origem, cor de pele, marcadores sociais, sabemos que os efeitos mais deletérios atingiram os trabalhadores afrodescendentes. Assim, encontramos ameaças ainda mais nocivas 
à sobrevivência desse segmento da classe trabalhadora. Por um lado, as tendências fascistas de um governo com pouco apreço aos valores democráticos burgueses e republicanos e, por outro, a racionalidade eugênica que tem ditado as ações e propostas do governo nas respostas providenciadas à sociedade.

No item a seguir trataremos das tendências fascistas e eugênicas do governo Bolsonaro nas respostas providenciadas a COVID-19 e os impactos disso para a classe trabalhadora, com enfoque na população negra.

\section{O FASCISMO E A EUGENIA COMO FORMAS DE AGIR E "PENSAR" DO GOVERNO BOLSONARO.}

Quando a pandemia da COVID-19 foi decretada pela Organização Mundial de Saúde em 11 de março de 2020, o ocidente ainda procurava maneiras de compreender a extensão e gravidade dessa situação. Uma das assertivas que mais se popularizou, nesse primeiro momento, foi a de que se trataria de um vírus "democrático", por equalizar os riscos de contaminação entre ricos e pobres com a máxima "estamos todos no mesmo barco".

Mas afinal, de que serve nosso entendimento sobre a democracia para entendermos esse vírus e sua relação com a produção e reprodução das relações sociais? Caso questionássemos as mesmas pessoas que anunciavam esse vírus como "democrático" sobre a compreensão que possuíam de democracia, o que possivelmente obteríamos como resposta? Suponhamos: "Democracia é o regime político da vontade da maioria" ou "Democracia é ir votar a cada 4 anos".

Essas respostas seriam plausíveis a qualquer um que equalize esse vírus à democracia. Todavia, reduzir a democracia à afirmação de que essa seria o regime político da maioria é algo problemático. A democracia não é meramente um regime da vontade da maioria, à medida que uma maioria não pode decidir de forma unívoca a direção da sociedade. Partir dessa afirmação para definir o que é a democracia é reduzi-la à volição de um coletivo que pode ser altamente pernicioso para valores republicanos. Basta realizarmos uma breve análise histórica sobre regimes políticos repressivos e a aprovação que tiveram junto à maioria da população ${ }^{5}$. A

\footnotetext{
${ }^{5} \mathrm{O}$ fascismo é o exemplo mais claro disso. Obras completamente distintas sobre isso, que versam sobre esse regime repressivo, podem partir de referenciais teóricos completamente distintos. Todavia, o ponto em comum ao qual não conseguem escapar é de que o fascismo historicamente foi não apenas um movimento das massas, mas
} 


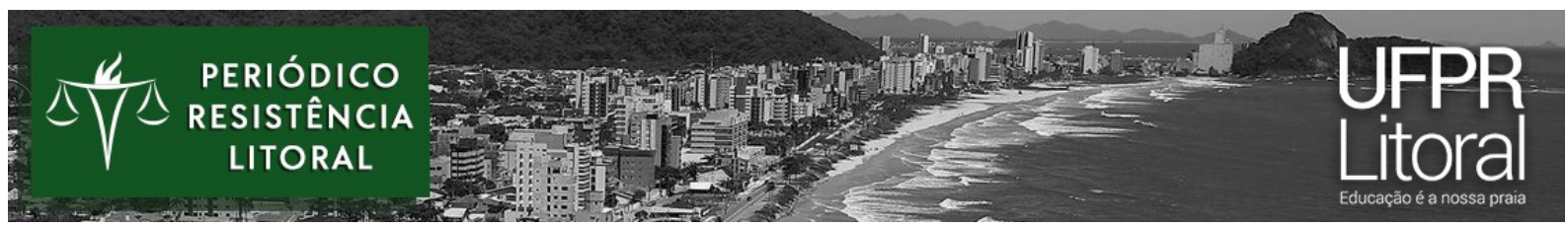

democracia também não deve ser reduzida ao ato de votar periodicamente de quatro em quatro anos, pois isso é uma concepção instrumental e pragmática em torno de um dos "rituais" - por assim dizer - dos processos democráticos. Votar é apenas um momento e que por isso não define por si no que consiste a democracia.

Dessa forma, precisamos colher da democracia aquilo que possui de mais particular e incompatível com outros regimes políticos. Enquanto um modo de organização da vida política, em uma sociedade historicamente determinada, a democracia é o único regime político que reconhece o conflito enquanto algo legítimo. Ela permite interrogar a autoridade, reconhece o dissenso como parte da vida pública e não se omite de questionar o projeto de sociedade que temos. Dizer que a democracia reconhece o conflito como algo legítimo significa dizer que na arena de lutas sociais a qual nos submetemos sobre seu jugo, os conflitos acabam por gerar direitos, que geram outros conflitos, que geram outros direitos (COUTINHO, 2000).

Dessa maneira, precisamos nos atentar ao fato de que, se há uma forma de refletirmos sobre a existência desse vírus em nossa sociedade, e a relação compossível desse com a democracia, é por via da centralidade da luta de classes que, como aponta Casimiro (2018), é repleta de falhas, incoerências e inconsistências em virtude de sua égide se dar, principalmente, em um país de passado colonial escravista com a dominação de uma burguesia atrasada, reacionária e com profundo desprezo por seu povo, história e imagem.

A respeito do início da propagação da COVID-19, esse vírus se disseminou tão rapidamente pelo globo em virtude da maneira como indivíduos detentores de recursos financeiros e materiais circulam, quase sem fronteiras. Em uma breve retrospectiva, o primeiro caso de COVID-19 confirmado no Brasil foi em 26 de fevereiro, um homem de 61 anos que havia viajado para a Itália. O segundo caso foi com um homem de 32 anos que havia estado também na Itália. O terceiro caso, confirmado no dia 04 de março, foi com outro homem que em uma viagem pela Europa visitou também a Itália. A partir do dia 5 de março, os casos começaram a apresentar um aumento significativo, com registro da primeira transmissão interna e sempre com o mesmo padrão: brasileiros/as que retornavam da Europa (cf. SANAR MED, 2020).

No dia 11 de março, a Organização Mundial de Saúde declarou estado de pandemia e no dia 13 de março o Ministério da Saúde regulamentou critérios de isolamento e quarentena

também uma requisição das massas. Isso pode ser observado em obras de Soares (2020), Eco (2018), Konder (2009) e Reich (1974). 


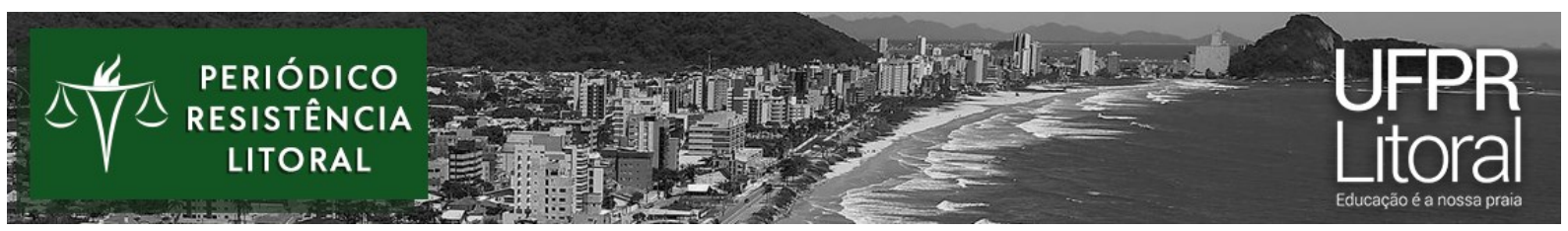

que deveriam ser aplicados pelas autoridades sanitárias em pacientes com suspeita ou confirmação de infecção pela COVID-19.

O perfil da primeira vítima fatal no Brasil, confirmada em 18 de março, sintetiza a tragédia que esse vírus representa aos segmentos mais vulneráveis da classe trabalhadora. Manoel Messias Freitas Filho, 62 anos, porteiro aposentado (TREVISAN, 2020). Após os primeiros casos e com o agravamento da pandemia no país, o perfil das vítimas foi se tornando cada vez mais claro - homens e mulheres, negros e pobres. Em um levantamento realizado pela consultoria Lagom Data, foram analisados dados sobre mais de 54.000 mortos por COVID-19 no Brasil e se conclui que são fatores preponderantes no perfil das vítimas a vulnerabilidade socioeconômica e sociodemográfica. Em sua disseminação, a doença matou mais pretos/as e pardos/as quando comparada proporcionalmente à população caucasiana (SOUZA, 2020). Embora no início o vírus tenha se concentrado entre elites e privilegiados que retornavam de viagens no exterior, logo sua disseminação ocorreu entre os segmentos mais vulneráveis da classe trabalhadora. Em verdade, a burguesia encontrou em sua realidade condições infinitamente superiores para realizar o chamado distanciamento físico ${ }^{6}$. Pois mesmo em um quadro de pandemia, a burguesia em seu distanciamento físico não abdica de explorar suas empregadas domésticas, babás, motoristas, entregadores, entre outros.

Para a burguesia, o distanciamento físico é possível pois há todo um conjunto de trabalhadores altamente descartáveis ao sistema que não possuem os meios para se protegerem e que, entre o risco da contaminação e a morte por inanição, se encontram impelidos a não cessarem suas atividades laborativas. E a isso, a COVID-19 possui aliados indispensáveis em nosso país: as precárias condições de vida da maior parte da população, o ódio e desprezo que nossas elites vociferam contra os pobres e um governo ignóbil, néscio, virulento e incapaz de responder a esse quadro de maneira minimamente responsável.

\footnotetext{
${ }^{6}$ O termo "isolamento social" é atualmente questionado em virtude da ininterrupta circulação de pessoas e mercadorias em nossa sociedade. O processo de consumo e de usufruto de serviços pressupõe fundamentalmente essa circulação. Logo, o isolamento social não é uma realidade possível principalmente nos centros urbanos, locais por excelência de concentração do vírus. Em virtude disso, o termo mais apropriado, apontado por epidemiologistas seria o distanciamento físico. Seguindo ainda recomendações da OMS, da Unicef e da União Europeia, a expressão "distanciamento físico" é mais adequado, reservando o termo "isolamento" para referir à restrição ou supressão de contatos interpessoais para sujeitos potencialmente infectados ou expostos. $\mathrm{O}$ distanciamento social seria um resultado colateral indesejável, tanto relativo ao contraste como à ou redução de relações sociais. Em suma, para a redução efetiva da transmissão numa epidemia, precisamos estar fisicamente separados, mas, para superar o potencial impacto negativo da pandemia sobre a saúde mental coletiva, devemos permanecer conectados social e afetivamente.
} 


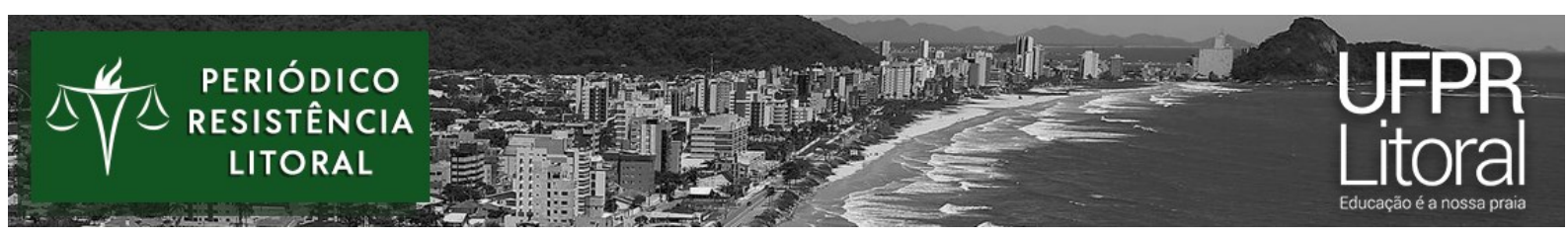

Quanto ao ódio e desprezo de nossas elites, são diversos os exemplos de empresários, figuras públicas e políticos que publicamente defenderam o primado da economia em detrimento da vida dos trabalhadores. O que evidencia que algumas vidas podem ser perdidas desde que a economia não pare. Capitalismo pavimentando a produção, circulação e consumo das mercadorias e serviços por meio de corpos que consome em sua movimentação. Se o capitalismo esbanja vidas e expropria a potência criadora da classe trabalhadora, a pandemia parece ofertar uma oportunidade para demonstrar o desapreço das classes dominantes pelos trabalhadores. À custa da vida de milhares de pessoas, a oportunidade de reformar o malogrado sistema econômico com a afirmativa "sairemos melhores e mais fortes dessa pandemia" basta que a economia não pare. Sabemos que a economia é movimentada em seus interstícios, no chão da fábrica, nas ruas pela classe trabalhadora e não por aquela classe que apregoa que não podemos abdicar do lucro e consegue por meio da exploração realizar o distanciamento físico em suas mansões, coberturas e ilhas privadas.

Em uma análise acerca das práticas e racionalidade que orientam o governo Bolsonaro, o fascismo passou a ser uma categorização constante para definir suas ações, ao mesmo tempo em que uma racionalidade oriunda da virada do século XIX e início do século XX, um tipo de ramo obscuro da ciência, no caso a eugenia, acabou sendo associado à forma de "pensar" mediante a pandemia.

O fascismo, sucintamente, seria uma ideologia política ultranacionalista e autoritária caracterizada por poder ditatorial, repressão da oposição por via da força e forte arregimentação da sociedade e da economia. Embora os partidos e movimentos fascistas apresentem divergências significativas entre si, é possível apontar várias características em comum, entre as quais nacionalismo extremo, desprezo pela democracia eleitoral e pela liberdade política e econômica, crença numa hierarquia social natural e no domínio das elites e o desejo de criar uma comunidade em que os interesses individuais sejam subordinados aos interesses da nação. O fascismo é oposto ao liberalismo e ao marxismo, posiciona-se na extrema-direita do espectro político (ECO, 2018).

O termo "fascismo" adapta-se a tudo porque é possível eliminar de um regime fascista um ou mais aspectos e continuará a ser reconhecido como fascista. E, a despeito dessa questão polimorfa, Eco (2018) indica uma lista de características típicas daquilo que denomina de "fascismo eterno". Tais características não podem ser reunidas em um sistema; muitas se contradizem entre si e são típicas de outras formas de despotismo ou fanatismo. Mas, é suficiente 


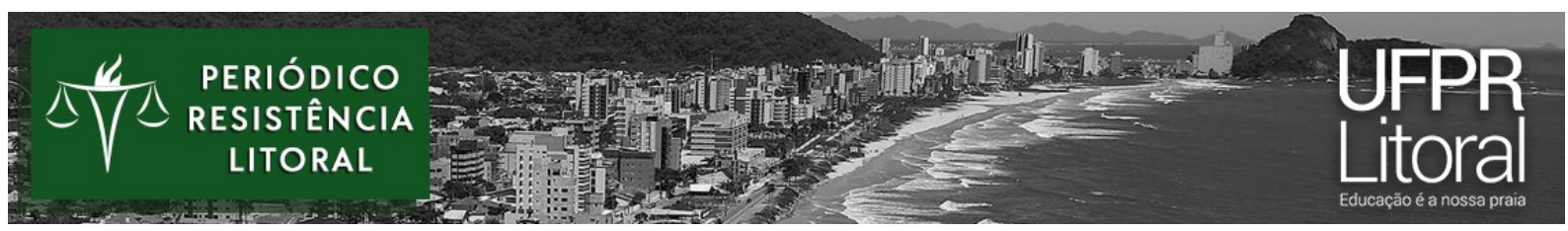

que uma delas se apresente para fazer com que se forme uma ameaça fascista: culto à tradição, recusa à modernidade, culto da ação pela ação, desacordo como traição, apelo às classes médias frustradas, obsessão pela ideia de uma constante conspiração, os inimigos são ao mesmo tempo fortes demais e fracos demais, pacifismo enquanto conluio com o inimigo já que a vida deve ser uma guerra constante, desprezo pelos fracos, a arma como símbolo fálico da autoridade, enfim, são diversas as características (ECO, 2018).

As atitudes do governo Bolsonaro já apontavam para uma guinada autoritária anterior a pandemia da COVID-19, conforme nos apresenta Soares (2020):

\begin{abstract}
A partir de janeiro de 2019, já no governo, suas práticas (Bolsonaro) têm buscado confrontar os poderes legislativo e judiciário, ofuscar a independência da mídia, hostilizar movimentos sociais, desconstituir a laicidade do Estado, cooptar as forças armadas (convertendo-as em apêndices do governo em vez de instituições do Estado), afrouxar controles e regulações que garantiam ou visavam garantir direitos trabalhistas e prevenir ou mitigar desmatamento de florestas, invasões de territórios indígenas e ações policiais violentas. O exercício do poder executivo tem se confundido com a agitação permanente da militância ultradireitista, nas ruas e nas redes, e a multiplicação artificial de focos de conflito a partir de acusações a complôs comunistas de globalistas, disseminação de fake News, teorias conspiratórias sinofóbicas de inspiração trumpista (SOARES, 2020, p. 11, grifo nosso).
\end{abstract}

Essa postura corrobora com outra característica do fascismo, a defesa da luta perpétua, do enfrentamento constante a todos os inimigos da nação, sejam esses internos ou externos. $\mathrm{O}$ fascismo não pode se permitir parar e por isso vai deflagrando crise atrás de crise. Esse modelo da batalha perpétua aparece também na defesa intransigente da economia enquanto componente central da sociedade. A tragédia sinalizada por esse aspecto aparece da seguinte forma: mesmo que seja de amplo conhecimento as precárias condições laborais da maior parte da classe trabalhadora, a economia não pode parar; mesmo sabendo das condições do transporte coletivo utilizada pelos/a trabalhadores/as, com aglomerações que potencializam a transmissão do vírus, a economia não pode parar; mesmo sendo de conhecimento, por parte de órgãos oficiais, que a maior parte das famílias brasileiras não dispõe de espaço adequado para realização do distanciamento físico, a economia não pode parar; mesmo sendo de conhecimento que a maior parte das famílias brasileiras são intergeracionais - aglutinam muitas vezes de 3 a 4 gerações em um mesmo domicílio - o que expõe grupos de risco em virtude da dinâmica da casa, transporte e trabalho, ainda assim, a economia não pode parar. 


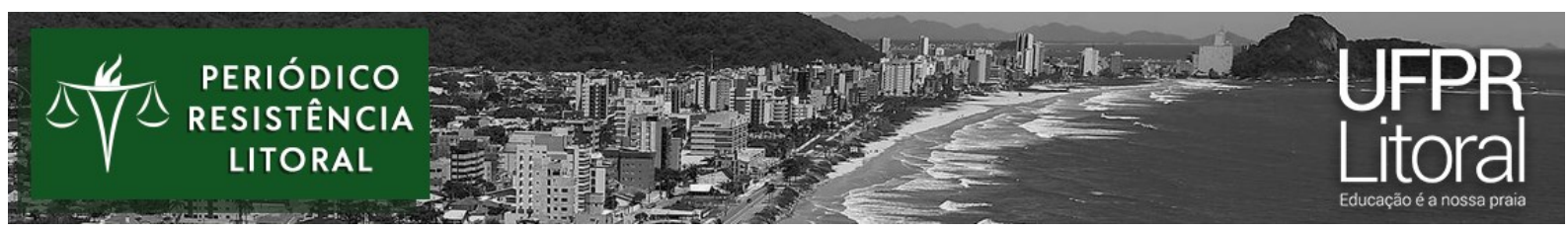

E isso revela uma outra faceta desse governo: as práticas políticas que permeiam sua conduta diante do outro (seja oponentes ou aliados) é o confronto, a produção ininterrupta de inimigos, o culto ao irracionalismo, o desprezo pela vida e essas tendências passam a ser justificadas e explicadas por meio da eugenia. A eugenia é a ciência do aperfeiçoamento racial, um tipo de racionalidade racista que, entre o final do século XIX e início do século $\mathrm{XX}$, foi assumida como uma teoria que exigia um conjunto de ações interventivas para o refinamento dos genes da raça humana. A eugenia sustenta-se na supremacia de um discurso racista dirigido aos inimigos externos da nação e aos inimigos internos que ameaçam o esplendor do Estado (DIWAN, 2015).

O passado escravista e colonizador, do qual diversos países fazem parte, encontraram na explicação ofertada pela eugenia formas de legitimar cientificamente o que era considerado como mera superioridade divina assegurada ao branco europeu. A eugenia, entre o final do século XIX e início do século XX, ratificou como premissas discursivamente científicas um conjunto de preconceitos sobre os povos originários da América e os descendentes dos sequestrados do continente africano submetidos à escravidão. E, ao mesmo tempo, permitia identificar o inimigo interno, os perigos de uma raça disgênica no interior da nação. Em especial, havia uma classe que entre o final do século XIX e início do século XX urgia ser eugenizada: a classe trabalhadora. Tratava-se de uma "classe perigosa" em seus desvios, que recusava a servidão, com seus doentes, crianças abandonadas, loucos, bêbados, mulheres operárias, imigrantes, negros e negras, prostitutas e comunistas (STEPAN, 2005).

A eugenia no Brasil esteve muito associada às práticas higienistas e sanitaristas. $\mathrm{O}$ imigrante que chegou para substituir a força de trabalho negra e assegurar o sucesso do processo de embranquecimento do país, apresentou diversas ameaças ao encaminhamento histórico da modernização econômica no país. Para isso, as práticas eugênicas no tratamento entre as diferenças das classes sociais foi uma constante tanto para o embranquecimento do país quanto para a disciplinarização da classe trabalhadora (STEPAN, 2005).

Essa característica histórica da forma como a eugenia se constituiu como um braço da ciência racista à serviço da classe dirigente, acena para a forma como esse mesmo discurso parece emergir novamente. Do final do século XIX e início do século XX para os dias de hoje, nos deparamos com um governo que rejeita as parcas conquistas democráticas alçadas desde $\mathrm{o}$ processo de redemocratização da sociedade brasileira e que repudia a emersão de sujeitos políticos que, por serem "disgênicos”, são ameaças a um tipo de esplendor do Estado que 


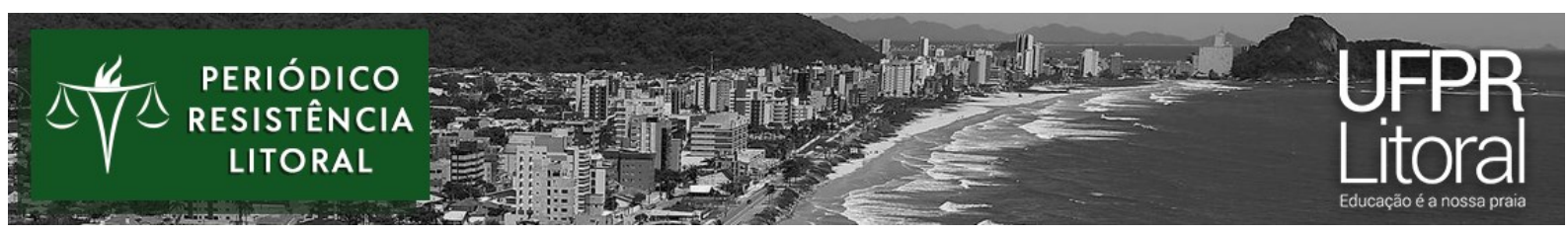

precisa se apoiar exclusivamente sobre o homem cisgênero, caucasiano, heterossexual, cristão e que esteja disposto a se armar para defender o Estado contra amplos segmentos da classe trabalhadora que galgaram importantes conquistas nos últimos anos na arena de lutas por direitos sociais.

A partir das premissas eugênicas é possível afirmar que esteve subjacente, nas práticas do governo e respostas ofertadas a respeito da pandemia da COVID-19, não um discurso anticientífico, mas um discurso amparado no eugenismo. Em entrevista ao Jornalismo da TV Cultura, em 11/05/20, o médico Arnaldo Lichtenstein, diretor do Hospital das Clínicas de São Paulo, afirma que a postura presidencial, ao minimizar a gravidade da Covid-19,

Não é um negacionismo da ciência isso, é uma linha de raciocínio muito diferente e cruel. Sabe-se que quando $70 \%$ das pessoas pegarem a doença o vírus arrefece, não é preciso parar a economia, os idosos em sua maioria vão morrer, os doentes também, e vão ficar os jovens e atletas. Isso se chama eugenia, lembre-se de que o sistema político mundial usava isso (LICHTENSTEIN, 2020, recurso em rede).

O resultado disso é que, no entendimento de certas figuras do governo, o distanciamento físico não é necessário e que se for para sacrificar alguém, que sejam os idosos dependentes do INSS pois, no fim, desoneraria os cofres públicos (LINDNER; VARGAS, 2020). A eugenia é aqui o entendimento de que sairemos mais fortes e melhores após essa pandemia, em virtude da "limpeza" biológica que será propiciada por ela.

O que se observa, é que as tendências fascistas desse governo quando combinadas com uma ameaça epidemiológica como a da COVID-19, resultam na proliferação de omissões e ações que objetivam expor a própria população, que é dispensável aos olhos desse governo, ao risco de morte, o qual só poderia ser contornado por distanciamento físico, algo sistematicamente recusado pela burguesia que não abdica da exploração dos trabalhadores, mesmo em meio a uma pandemia.

\section{CONSIDERAÇÕES FINAIS}

Diante desses breves, porém fundamentais elementos, é possível compreender que a luta de classes no Brasil é necessariamente atravessada pelas categorias raça, classe e gênero. Através da universalização de uma representação de sujeito coletivo da classe burguesa mundial (homem, branco, hetero, cis gênero), sob bases de teorias eugenistas e patriarcais e do modelo 


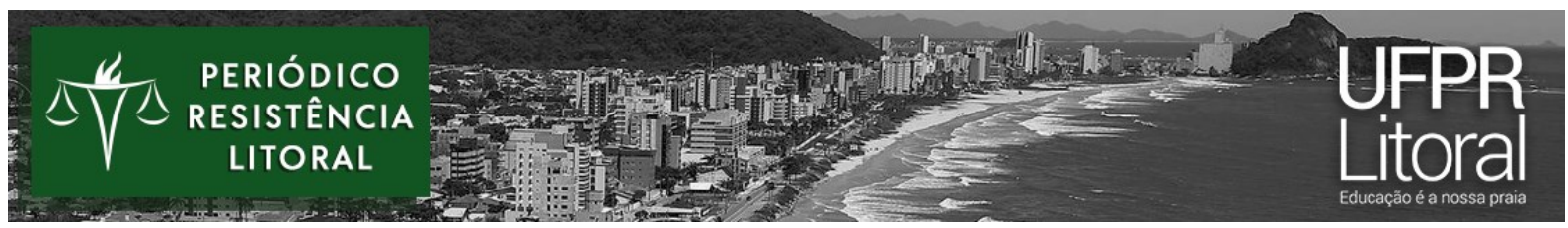

de produção capitalista imperialista, a classe burguesa brasileira pôde se utilizar do racismo e do machismo como tecnologias de incremento da produção e da extração de mais valia absoluta e relativa, ampliando as taxa de lucro através da deslegitimação do valor da força de trabalho de segmentos da classe trabalhadora, mais do que outros.

Ademais, a falta histórica de políticas públicas sociais ou a precarização das existentes além de intensificarem o genocídio da população negra, pobre e periférica pelo não acesso à condições básicas de sobrevivência, provoca a segregação espacial e a pauperização extrema com cor e endereço, agigantando o número de trabalhadores na condição de superpopulação relativa, expostos às precárias condições do trabalho informal.

Não existe distanciamento físico possível à classe trabalhadora mediante um quadro de tamanha pauperização e desigualdade social. Em nossa sociedade, já entendemos que o distanciamento físico foi usufruído por poucos e hoje, o que se coloca como possível a classe trabalhadora, é a luta nas ruas contra a ascensão de um governo paramilitar e fascista, uma obrigação de todos e todas brasileiros e brasileiras, não só em defesa da vida, na luta pela garantia de sobrevivência de um segmento da população que está sendo historicamente dizimado, mas também para findar a reprodução do modelo de sociedade alicerçado sob a riqueza de poucos, em detrimento da vida de muitos. Por fim, reforçamos e divulgamos o manifesto do coletivo Coalizão Negra por Direitos que "enquanto houver RACISMO, não haverá DEMOCRACIA."”

\section{REFERÊNCIAS}

ALMEIDA, Silvio Luiz de. Racimo Estrutural. São Paulo: Sueli Carneiro; Pólen, 2019. 264 p. (Feminismos Plurais / coordenação de Djamila Ribeiro).

BAMBIRRA, Vânia. Capitalismo dependente latino-americano. $2^{\mathrm{a}}$ edição. Florianópolis: Insular: 2013 (coleção Pátria Grande).

CASIMIRO, Flávio Henrique Calheiros. A nova direita: aparelhos de ação política e ideológica no Brasil contemporâneo. / Flávio Henrique Calheiro Casimiro. - 1.ed. - São Paulo: Expressão Popular, 2018. 583 p.

\footnotetext{
${ }^{7}$ COALIÇÃO NEGRA POR DIREITOS. Enquanto houver racismo não haverá democracia. 2020. Disponível em: $<$ https://comracismonaohademocracia.org.br/ > . Acesso em 06 de jul. de 2020.
} 


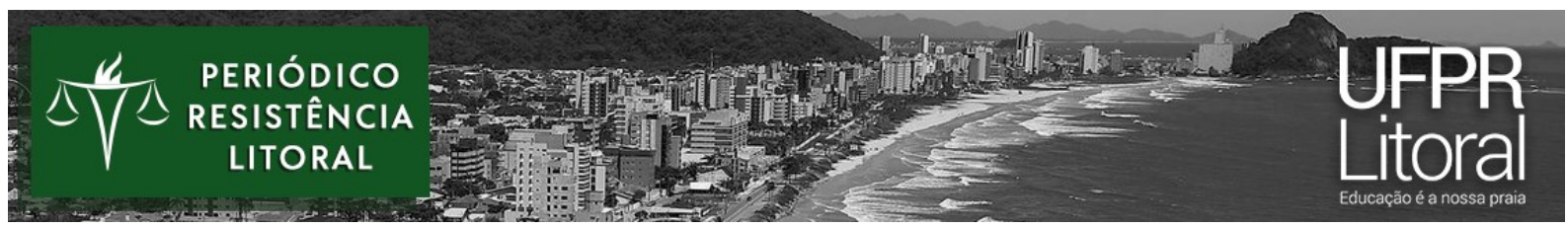

COUTINHO, Carlos Nelson. Conta a corrente: Ensaios sobre democracia e socialismo. São Paulo: Cortez, 2000.

DIWAN, Pietra. Raça Pura: uma história da eugenia no brasil e no mundo. São Paulo: Contexto, 2015.

ECO, Umberto. O Fascismo Eterno. São Paulo: Record, 2018.

GONZALEZ, Lélia. Por um Feminismo afro-latino-americano. In: Lélia Gonzalez. Orgs RIOS, Flávia; LIMA, Márcia. Rio de Janeiro: Zahhar, 2020.

IANNI, O. Capitalismo, escravidão e trabalho livre. In: FERNANDES, F. Comunidade e Sociedade no Brasil: leituras básicas de introdução ao estudo macrossociológico do Brasil. Editora Nacional / Editora da USP: São Paulo, 1972.

KONDER, Leandro. Introdução ao Fascismo. São Paulo: Expressão Popular, 2009 (Coleção Assim Lutam os povos).

LICHTENSTEIN, Arnaldo: "Isso se chama eugenia, lembre-se de que sistema político mundial usava isso". Jornal da Cultura, 11 maio 2020. Disponível em: < https://www.youtube.com/watch?v=TDztePweQqc >. Acesso em: 03 jul. 2020.

LINDNER, Julia; VARGAS, Mateus. Morte de idosos por Covid 19 melhora contas da Previdência. O Estadão. São Paulo, p. 1-2. maio 2020. Disponível em: https://economia.estadao.com.br/noticias/geral,morte-de-idosos-por-covid-19-melhora-contasda-previdencia-teria-dito-chefe-da-susep,70003317874. Acesso em: 14 jun. 2020.

MARX, K. A Miséria da Filosofia. São Paulo: Editora Escala, 2007. (Coleção Grandes Obras do Pensamento Universal - vol. 77).

NETTO, José Paulo. Capitalismo Monopolista e Serviço Social. $8^{\mathrm{a}}$ ed. São Paulo: Cortez, 2011.

REICH, Wilhelm. Psicologia de Massa do Fascismo. Porto: Publicações Escorpião, 1974 (Biblioteca Ciência e Sociedade).

SANAR MED. Linha do tempo do Coronavírus no Brasil. 2020. Disponível em: https://www.sanarmed.com/linha-do-tempo-do-coronavirus-no-brasil. Acesso em: 14 jun. 2020.

SCHWARCZ, L. M., STARLING, H. M. Brasil: Uma Biografia. São Paulo: Companhia das Letras, 2015.

SOARES, Luiz Eduardo. Dentro da Noite Feroz [recurso eletrônico]: o fascismo no Brasil. São Paulo: Boitempo, 2020. Recurso digital. 


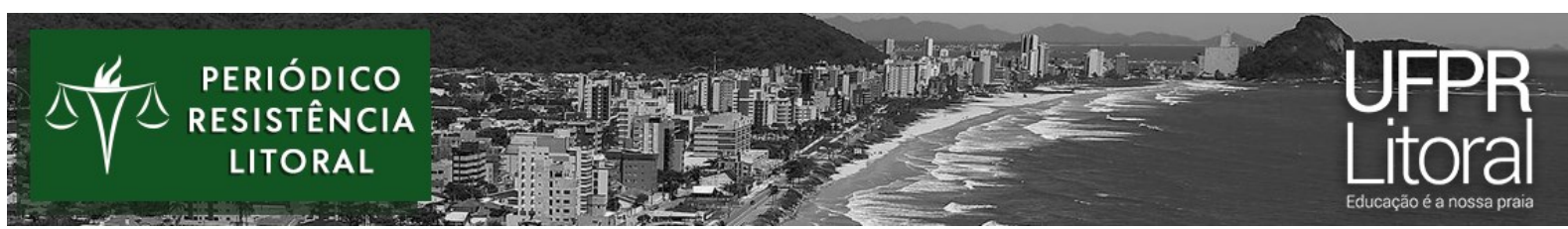

SOUZA, Marcelo. DADOS DO SUS REVELAM VÍTIMA-PADRÃO DE COVID-19 NO BRASIL: HOMEM, POBRE E NEGRO. Época, São Paulo, p. 1 - 2, 3 jul. 2020. Disponível em: https://epoca.globo.com/sociedade/dados-do-sus-revelam-vitima-padrao-de-covid-19-nobrasil-homem-pobre-negro-

24513414?utm_source=Facebook\&utm_medium=Social\&utm_campaign=compartilhar.

Acesso em: 3 jul. 2020.

STEPAN, Nancy Leys. "A Hora da Eugenia": raça, gênero e nação na américa latina. Rio de Janeiro: Fiocruz, 2005. (Coleção História e Saúde).

TAUNAY. Carlos Augusto. Manual do Agricultor Brasileiro. São Paulo: Companhia das Letras, 2001.

TREVISAN, Daniel. Seu Manuel, primeira vítima fatal do coronavírus. Diário do Centro Mundo. São Paulo, p. 1-2. mar. 2020. Disponível em: https://www.diariodocentrodomundo.com.br/seu-manuel-primeira-vitima-fatal-docoronavirus-e-o-retrato-do-brasileiro-que-mais-sofrera-pobre-e-que-nunca-viajou-para-oexterior-por-daniel-trevisan/. Acesso em: 14 jun. 2020. 